\title{
The cost-utility of open prostatectomy compared with active surveillance in early localised prostate cancer
}

Florian Koerber $^{1 *}$, Raphaela Waidelich², Björn Stollenwerk ${ }^{1}$ and Wolf Rogowski ${ }^{1,3}$

\begin{abstract}
Background: There is an on-going debate about whether to perform surgery on early stage localised prostate cancer and risk the common long term side effects such as urinary incontinence and erectile dysfunction. Alternatively these patients could be closely monitored and treated only in case of disease progression (active surveillance). The aim of this paper is to develop a decision-analytic model comparing the cost-utility of active surveillance (AS) and radical prostatectomy (PE) for a cohort of 65 year old men with newly diagnosed low risk prostate cancer.

Methods: A Markov model comparing PE and AS over a lifetime horizon was programmed in TreeAge from a German societal perspective. Comparative disease specific mortality was obtained from the Scandinavian Prostate Cancer Group trial. Direct costs were identified via national treatment guidelines and expert interviews covering in-patient, out-patient, medication, aids and remedies as well as out of pocket payments. Utility values were used as factor weights for age specific quality of life values of the German population. Uncertainty was assessed deterministically and probabilistically.

Results: With quality adjustment, AS was the dominant strategy compared with initial treatment. In the base case, it was associated with an additional 0.04 quality adjusted life years (7.60 QALYs vs. 7.56 QALYs) and a cost reduction of $€ 6,883$ per patient (2011 prices). Considering only life-years gained, PE was more effective with an incremental cost-effectiveness ratio of $€ 96,420 /$ life year gained. Sensitivity analysis showed that the probability of developing metastases under AS and utility weights under AS are a major sources of uncertainty. A Monte Carlo simulation revealed that AS was more likely to be cost-effective even under very high willingness to pay thresholds.

Conclusion: AS is likely to be a cost-saving treatment strategy for some patients with early stage localised prostate cancer. However, cost-effectiveness is dependent on patients' valuation of health states. Better predictability of tumour progression and modified reimbursement practice would support widespread use of AS in the context of the German health care system. More research is necessary in order to reliably quantify the health benefits compared with initial treatment and account for patient preferences.
\end{abstract}

Keywords: Economic evaluation, Cost-utility analysis, Cost-effectiveness, Prostate cancer, Active surveillance, Decision analysis, Early evaluation

\footnotetext{
* Correspondence: florian.koerber@helmholtz-muenchen.de

'Institute for Health Economics and Health Care Management, Helmholtz Zentrum Munich, German Research Center for Environmental Health (GmbH), Ingolstädter Landstrasse 1, 85764 Neuherberg, Germany

Full list of author information is available at the end of the article
} 


\section{Background}

Prostate cancer (PC) - ICD code C.61 'Malignant neoplasm of the prostate' following ICD-10-GM classification - is the second most frequent cancer among males in economically developed countries and the most common cancer in Germany, accounting for 14\% and 25\% of total new cancer cases respectively [1]. Since 1990, the number of new cases has risen by over $50 \%$, amounting to more than 80,000 new diagnoses in Germany in 2010 [2]. The increase in PC incidence has been related to improved means of early diagnosis, especially through prostate-specific antigen (PSA) testing [3]. Prostatectomy (PE) is the first line treatment option for early stage PC. PE is considered the gold standard in urology because other options such as radiotherapy (RT) cannot guarantee complete elimination of tumour cells in the prostate [4,5]. It is also the only treatment for which there exists favourable high quality clinical evidence [6,7]. Accordingly, the German Federal Joint Committee ('Gemeinsamer Bundesausschuss', GBA) decided that PE is the preferred treatment option for early stage $\mathrm{PC}$ in low risk patients because of the lack of prospective, randomised evidence for RT [6].

Because most carcinomas are thought to have a protracted natural history and more than $85 \%$ of patients are older than 65 years at the time of diagnosis, most patients die with the disease and not of it $[8,9]$. This is especially true for carcinomas that exhibit a low risk profile, i.e. a low PSA value, no histological conspicuity suggested by an indicator such as the Gleason score and confinement to the prostate. For such men, the risk of over-treatment is associated with negative health impacts resulting from the adverse effects of prostatectomy $[10,11]$. Postoperative rates of incontinence (IC) or erectile dysfunction (ED) of $97 \%$ and $72 \%$, respectively, have been reported within 90 days of PE [12]. Despite the fact that some patients recover in the long term, these adverse effects (AE) significantly reduce health related quality of life [13].

As a consequence, observing strategies have been proposed as an alternative to initial treatment $[11,14]$. Watchful waiting (WW) is a strategy from the pre-PSA test era for patients with limited life expectancy. WW implies no intention to initiate curative treatment. In case of symptomatic disease progression, only palliative treatment is offered to patients, and a survival benefit of primary treatment with PE over WW has been documented in a prospective, randomised controlled trial (RCT) $[7,15]$. Active surveillance (AS), on the other hand, describes a policy of close monitoring for patients with a life expectancy $>15$ years. In cases of disease progression, curative treatment is triggered.

There exists no evidence from RCTs for AS [16]. Because AS implies close monitoring and curative treatment when necessary, it can reasonably be assumed that an AS strategy is more effective in avoiding PC specific death than WW. In fact, some evidence suggests that there is no difference in PC death to be expected between AS and PE [17]. The aim of this article was to develop a Markov model for the evaluation of AS as an alternative strategy to PE for the treatment of early stage, localised prostate cancer in the context of the German health care system. Owing to the lack of evidence for AS, we had to base our analysis on reasonable assumptions which we then challenged using extensive sensitivity analyses.

\section{Methods \\ Evaluation}

A decision analytic cost-utility model was developed following the standard of the CHEERS checklist, a general guideline on decision-analytic modelling [18]. It was performed from the perspective of the citizens insured by German Statutory Health Insurance (SHI), which is recommended by the German Institute for Quality and Efficiency in Health Care (IQWIG) and includes costs for SHI and out of pocket payments [19]. The study population consisted of men newly diagnosed with low risk PC, no other severe comorbidities and a life expectancy of $>15$ years. Low risk PC is characterised by a PSA value $\leq 10 \mathrm{ng} / \mathrm{ml}$, Gleason score $\leq 6$ and tumour stage $\leq \mathrm{T} 2 \mathrm{a}$ [11].

Men enter the model at the age of 65 years, which corresponds to the mean age of the cohort in the underlying clinical study. A Markov model was chosen to represent this cohort's course of disease through different states over time. Quarter-yearly transition cycles were assumed because significant changes in tumour states could occur after 90 days and long term adverse effects could be apparent. In order to capture the full range of costs and effects, we applied a lifetime horizon of 35 years, assuming an age limit of 100 years.

Health outcomes were measured in quality adjusted life years (QALYs), as quality of life is a central aspect in the decision whether to treat or not. All costs $(€)$ were adjusted to 2011 values. Both health outcomes and costs were discounted by $3 \%$, and the half-cycle correction was applied. The model was implemented in TreeAge Pro 2012.

\section{Interventions/model structure}

The German Association for Urology has published guidelines for the treatment of PC that include AS. According to these, AS involves 3-monthly determinations of PSA value and digital rectal examinations (DRE) in the first 2 years after diagnosis and bi-annually thereafter [5]. Additionally, a biopsy should be taken in the first year and every 3 years after. Treatment can be triggered 
by an indication of local progression through any of these parameters as well as patient choice. Patients aged $\leq 72$ years are treated by open radical PE; older patients receive RT. A recent review revealed no RCTs comparing the effectiveness of RT and PE with respect to PC mortality [20]. Conservatively, it was assumed that RT and PE have the same disease related outcomes. Downstream treatments such as treatment of adverse effects, prostate hyperplasia and advanced disease were assumed not to have an influence on the difference in mortality between AS and PE. Despite close monitoring, rapidly growing tumours might progress unnoticed under AS and develop metastases prior to treatment [21,22]. Complications occurring within 30 days of PE include rectal injury, wound infection, haemorrhage requiring blood transfusion, deep vein thrombosis and myocardial infarctions [23]. Short term adverse effects such as ED and/or IC are characterised by occurrence and resolution within 90 days after surgery. Long term adverse effects persist after 90 days and can be cured only by surgical intervention. In cases of local recurrence after initial PE, RT is the primary treatment option [5]. As with PE, the adverse effects of RT can be divided into short term and long term effects. In addition to IC and ED, bowel problems (BP) such as abdominal pain, bloating and diarrhoea may develop [24]. Local recurrence is a prerequisite for developing metastatic disease after initial treatment. Once metastases have developed, there is no chance of cure and patients will eventually die of prostate cancer (Figure 1) [25].

\section{Utilities}

\section{Baseline utilities}

Age-adjusted utility values from the general population provide a reasonable approximation when condition specific baseline data are not available [26]. Health state specific utilities were thus applied as a multiplicative factor to average, age-adjusted utilities from the German male population. The latter are based on a representative study among German citizens $(\mathrm{n}=2,049)$ surveying the EQ-5D items in the years 2006-2011 [27]. Based on these data, the functional relationship between mean EQ-5D utilities and age was estimated with a generalised

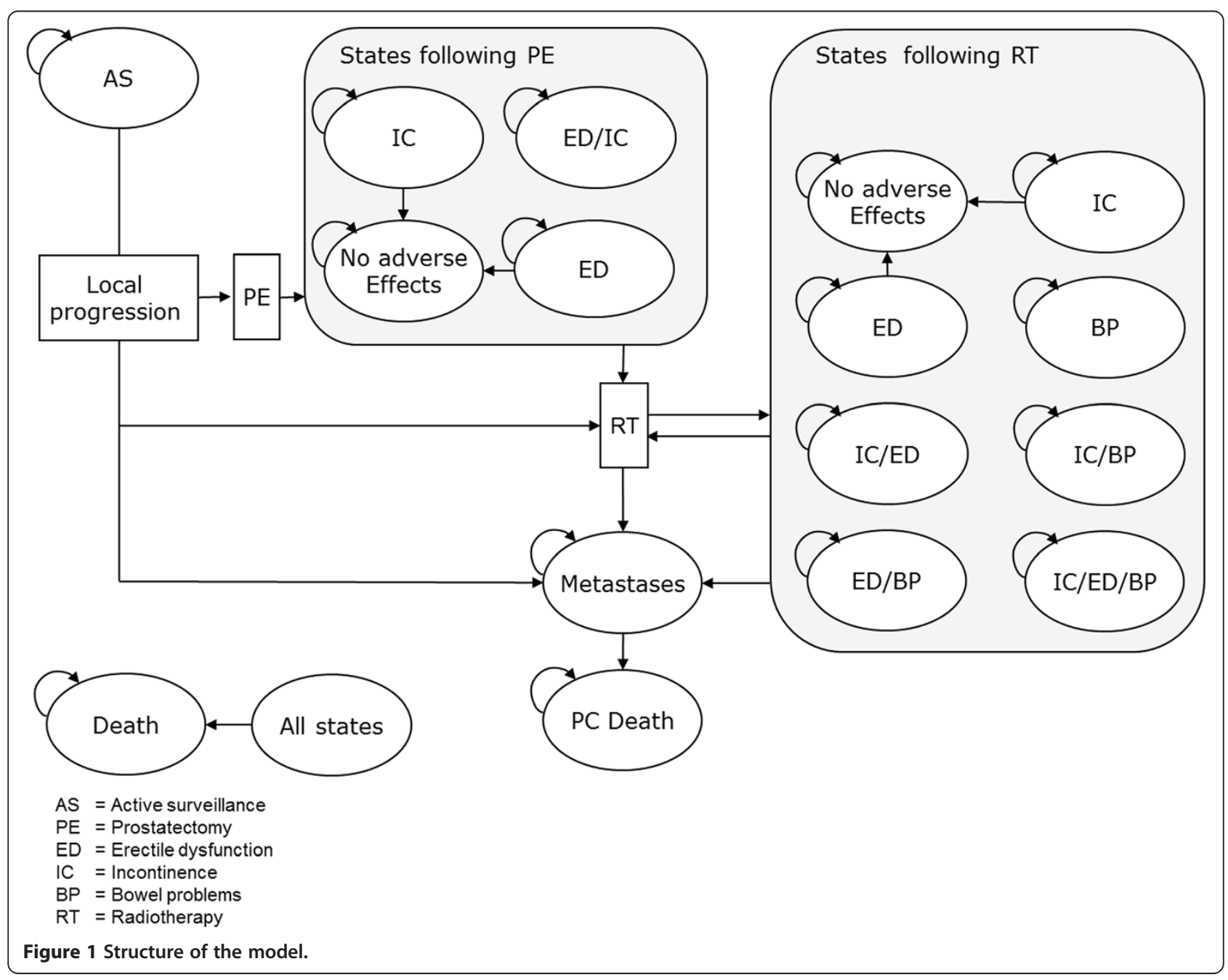


additive regression model using cubic regression splines (Figure 2) [25].

\section{Health state specific utilities}

We identified five studies that reported utility weights for relevant health states. Two of these presented implausible or inconsistent results because combined adverse effects were valued more highly than single ones or utility weights $>1$ were possible, respectively $[28,29]$. One recent study reported values depending on age and socio-economic status, which could not be adequately combined with our baseline utilities [30]. Stewart et al. provide mean utilities for postoperative health states from a cohort of 162 men [31]. These values compare well with the results of Sommers et al. [32]. Stewart et al. additionally reported utility values for treatment states and combined adverse events, such as ED and IC. Utility values for combined adverse events were surveyed as separate health states so no combination method had to be applied. Furthermore, the quality of life effects of conservative, i.e. non-surgical, downstream treatments such as incontinence pads were already incorporated in the description of health states. We therefore decided to use their preference-based set of utilities elicited by the standard gamble method. Following Liu et al. and the results of the meta-analysis by Bremner et al., we assumed that life under AS has the same utility as life after treatment without side effects [28,33] (Table 1).

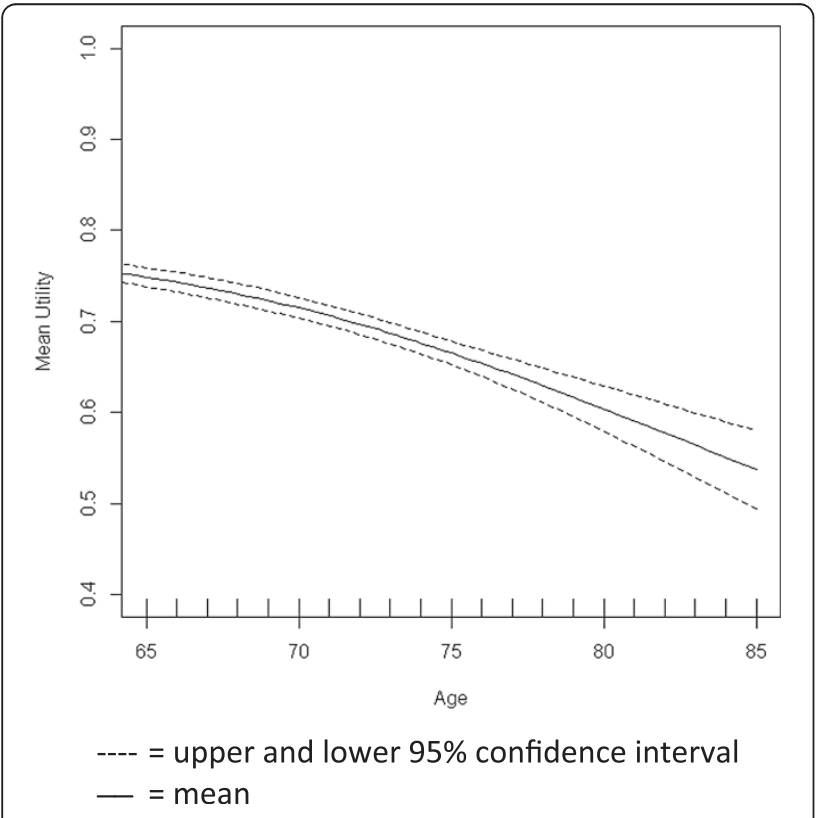

Figure 2 Age adjusted baseline utility German population.
Table 1 Utility weights of relevant health states

\begin{tabular}{|c|c|c|c|c|}
\hline State & $\begin{array}{l}\text { Expected } \\
\text { value }\end{array}$ & SE & $95 \% \mathrm{Cl}$ & Source \\
\hline During AS & 0.99 & 0.05 & $1 ; 0.9$ & $\begin{array}{c}\text { Bremner [28], } \\
\text { Liu [33], } \\
\text { own calculation }\end{array}$ \\
\hline $\begin{array}{l}\text { Urinary difficulty } \\
\text { during AS }\end{array}$ & 0.89 & 0.024 & $0.91 ; 0.85$ & Steward 2005 \\
\hline During PE treatment & 0.67 & 0.041 & $0.75 ; 0.59$ & Steward 2005 \\
\hline During radiotherapy & 0.73 & 0.045 & $0.82 ; 0.64$ & Steward 2005 \\
\hline $\begin{array}{l}\text { Post treatment no } \\
\text { adverse effects }\end{array}$ & 0.99 & 0.05 & $1 ; 0.9$ & $\begin{array}{c}\text { Bremner [28], } \\
\text { Liu [33], } \\
\text { own calculation }\end{array}$ \\
\hline Post treatment IC & 0.83 & 0.022 & $0.87 ; 0.79$ & Steward 2005 \\
\hline Post treatment ED & 0.89 & 0.013 & $0.92 ; 0.86$ & Steward 2005 \\
\hline Post treatment BP & 0.71 & 0.021 & $0.75 ; 0.67$ & Steward 2005 \\
\hline ost treatment IC, ED & 0.79 & 0.033 & $0.86 ; 0.72$ & Steward 2005 \\
\hline Post treatment IC, BP & 0.70 & 0.036 & $0.77 ; 0.63$ & Steward 2005 \\
\hline Post treatment ED, BP & 0.57 & 0.039 & $0.65 ; 0.49$ & Steward 2005 \\
\hline Post treatment IC, ED, BP & 0.45 & 0.044 & $0.54 ; 0.36$ & Steward 2005 \\
\hline Metastatic disease & 0.25 & 0.015 & $0.28 ; 0.22$ & Steward 2005 \\
\hline
\end{tabular}

AS = Active surveillance.

$\mathrm{PE}=$ Prostatectomy.

$\mathrm{IC}=$ Incontinence.

$\mathrm{ED}=$ Erectile Dysfunction

$\mathrm{BP}=$ Bowel Problems

\section{Costs}

Following the perspective of citizens insured by German SHI, all direct medical costs incurred by the SHI as well as by individual patients were included [19]. Indirect costs were neglected as the study population has passed retirement age. Equally, post hospital rehabilitation was not considered as it is typically covered by pension funds. Resource usage was identified and quantified through literature research and treatment recommendations from the Association of German Urologists. Out-patient unit prices are based on the physician's fee catalogue 2011 (0.035048 cents/point) [34]. In-patient unit prices are based on diagnosis related group (DRG) weights from the German DRG catalogue and the federal base rate for 2011 of $€ 2,963$ [35]. For the pricing of pharmaceuticals, we referred to the German formulary 2011 [36]. Remedies and other aids were valued according to market prices investigated using internet research as well as telephone interviews.

\section{Primary treatments}

In the German DRG system, re-hospitalisations within 30 days are coded as one case. Hence, the costs of PE with and without complications are reflected by the respective DRGs (Table 2). Postoperative monitoring takes place on an out-patient basis (Table 3). Physicians can bring to account a maximum of four patient visits per 
Table 2 In-patient costs of prostatectomy

\begin{tabular}{lll}
\hline In-patient treatment & DRG & Total costs $(\boldsymbol{\epsilon})$ \\
\hline Prostatectomy & M01B & 6,886 \\
Complications & M01A & 9,526 \\
\hline
\end{tabular}

annum. AS implies determination of PSA values, DRE and regular biopsies (Table 4). Despite preventive antibiotics, biopsy may cause urosepsis which requires hospitalization [37]. Furthermore, symptoms of benign prostate hyperplasia can develop in patients under AS. We assumed that initially half these patients are treated with alpha- 1 adrenergic antagonists (Tamsulosin) and the other half with 5-alpha-reductase inhibitors (Finasteride). Patients experiencing worsening of symptoms of urinary difficulty require surgical intervention with transurethral resection of the prostate (TURP) (Table 5). RT is undertaken by a specialist practitioner. Curative treatment entails two target volumes with a maximum of 72 gray, which is equivalent to 40 times 1.8 gray (Table 6).

\section{Adverse effects}

The numbers of general practitioner (GP) and specialist practitioner (SP) consultations due to diagnosis of erectile dysfunction were derived from a costing study by Wilson et al. [38]. We estimated consumption of remedies and aids based on the assumption that $70 \%$ of patients would make use of phosphodiesterase (PDE) inhibitor and $10 \%$ of cavernous injections, SKAT/MUSE or a vacuum pump respectively (Table 7). Symptomatic treatment of IC is achieved through the use of pads in the majority of patients (90\%). We assumed an equal distribution of strong, medium and low pads and an average use of three pads/day. Diapers or permanent catheters are necessary in $5 \%$ of all patients (Table 8 ). Costs of managing BP were based on a publication by Hummel et al. [20].

\section{Metastases}

Metastatic stage is characterised by two phases. At first, cancer is responsive to treatment with luteinizing hormone-releasing hormone (LHRH) agonists which

Table 3 Out-patient costs of prostatectomy

\begin{tabular}{lcccccccc}
\hline Item & $\begin{array}{c}\text { Quantity } \\
\text { p.a. }\end{array}$ & Price/unit $(\boldsymbol{\epsilon})$ & \multicolumn{4}{c}{$\begin{array}{c}\text { Total costs } \\
\text { p.a. }(\boldsymbol{\epsilon})\end{array}$} \\
\hline Follow-up year & $<2$ & $2-4$ & $>4$ & & $<2$ & $2-4$ & $>4$ \\
PSA value & 4 & 2 & 1 & 4.8 & 19.20 & 9.60 & 4.80 \\
Consultation fee & 4 & 2 & 1 & 1.75 & 7.00 & 3.5 & 1.75 \\
Treatment fee & 4 & 2 & 1 & 21.20 & 84.80 & 42.40 & 21.20 \\
$>$ 60 yrs & & & & & & & \\
Insuree lump sum & 4 & 2 & 1 & 9.11 & 36.45 & 18.22 & 9.11 \\
\hline
\end{tabular}

PSA = Prostate Specific Antigen
Table 4 Out-patient costs of active surveillance

\begin{tabular}{|c|c|c|c|c|c|c|c|}
\hline \multirow{2}{*}{$\frac{\text { Item }}{\text { AS year }}$} & \multicolumn{3}{|c|}{ Quantity p.a. } & \multirow[t]{2}{*}{ Price/unit (€) } & \multicolumn{3}{|c|}{ Total costs p.a. $(€)$} \\
\hline & 1 & 2 & $>2$ & & 1 & 2 & $>2$ \\
\hline DRE & 4 & 4 & 2 & & \multicolumn{3}{|c|}{ Included in lump sum } \\
\hline PSA value & 4 & 4 & 2 & 4.80 & 19.20 & 19.20 & 9.60 \\
\hline Biopsy & 1 & 0.33 & 0.33 & 18.58 & 18.58 & 6.19 & 6.19 \\
\hline $\begin{array}{l}\text { Consultation } \\
\text { fee }\end{array}$ & 4 & 4 & 1 & 1.75 & 7.01 & 7.01 & 1.75 \\
\hline $\begin{array}{l}\text { Treatment fee } \\
>60 \text { yrs }\end{array}$ & 4 & 4 & 2 & 21.20 & 84.82 & 84.82 & 42.41 \\
\hline $\begin{array}{l}\text { Insuree lump } \\
\text { sum }\end{array}$ & 4 & 4 & 2 & 9.11 & 36.45 & 36.45 & 18.22 \\
\hline \multicolumn{8}{|l|}{ Medication } \\
\hline $\begin{array}{l}\text { Antibiotics } \\
\text { (preventive) }\end{array}$ & 0.5 & 0.16 & 0.16 & 16 & 8.00 & 2.64 & 2.64 \\
\hline Sum & & & & & 174.05 & 156.33 & 80.84 \\
\hline
\end{tabular}

DRE $=$ Digital Rectal Examination

PSA $=$ Prostate Specific Antigen.

delay progression. Following treatment guidelines, we assumed a dose of $11.5 \mathrm{mg}$ every 3 months. Eventually, patients will become refractory and require chemotherapy. Chemotherapy implies treatment with $142.5 \mathrm{mg}$ of Docetaxel and $5 \mathrm{mg}$ of Prednisolone every 3 weeks. Additionally, around $70 \%$ of all refractory patients will develop bone metastases which are treated with zoledronic acid and RT (Table 9) [39]. Radiation therapy assumes a target volume of 35 gray, i.e. 14 times 2.5 gray.

\section{Probabilities}

\section{Mortality}

No RCTs comparing disease related mortality of PE and AS could be found in the literature [16]. One American and one Scandinavian RCT were identified comparing WW and initial treatment $[7,40]$. The 10-year results of the American study (PIVOT) reported overall PC death of $5.8 \%$ and $8.4 \%$ in the PE and observation arms respectively [40]. This corresponds to a relative risk (RR) of 0.69 which is more favourable towards WW than the results of the Scandinavian Prostate Cancer Group (SPCG). The difference in results is likely to be because the PIVOT cohort represented a population with less advanced disease [40]. However the PIVOT sample also included a large number of African Americans (>30\%) who have been shown to suffer from an increased risk of developing and dying from PC $[41,42]$. In order to avoid country specific bias, we chose to use the SPCG data, which represent the European population more realistically. The SPCG trial found that PE significantly reduced the risk of PC death 15 years after diagnosis with a $\mathrm{RR}=$ 0.62, $95 \%$ confidence interval $(\mathrm{CI}) 0.44,0.87$. RR over the time period was estimated by the authors using Cox proportional hazard models. However, the study 
Table 5 Costs other

\begin{tabular}{|c|c|c|c|c|}
\hline Item & DRG & Quantity p.a. & Price/unit $(€)$ & Total costs p.a. (€) \\
\hline \multicolumn{5}{|l|}{ In-patient treatment } \\
\hline \multicolumn{5}{|l|}{ Surgical } \\
\hline Prosthesis* & M03C, ZE 58 & 1 & 10238.03 & \\
\hline Sphincter* & M01B, ZE 10 & 0.5 & 6393.77 & 3196.14 \\
\hline Sling* & L06A, ZE139 & 0.5 & 3677.58 & 1388.79 \\
\hline Treatment of urosepsis & T60E & 1 & 3075.59 & \\
\hline TURP & $\mathrm{M} 02 \mathrm{~A}$ & 1 & 3768.93 & \\
\hline \multicolumn{5}{|l|}{ Out-patient treatment } \\
\hline \multicolumn{5}{|l|}{ BPS medication } \\
\hline Finasteride (5 mg, N3) & & 1.825 & 139.88 & 255.28 \\
\hline Tamsulosin (0.4 mg, N3) & & 1.825 & 96.43 & 175.98 \\
\hline
\end{tabular}

*not covered by statutory health insurance (out of pocket).

BPS $=$ Benign prostate syndrome.

TURP $=$ Transurethral resection of the prostate.

population ( $\mathrm{n}=695$, mean age 64.7 years) included men with more advanced disease, i.e. PSA value $<50$, tumour stage $\leq \mathrm{T} 2$ and Gleason score $\leq 10$. Furthermore, patients in the WW group were only treated palliatively in case of disease progression [43]. Following Pearson et al. in the base case, we thus assumed that only half the treatment benefit of PE would be maintained when compared with AS corresponding to a RR of 0.81. This also makes our base case results comparable to the study by Hayes et al. who assume that AS would be $25 \%$ more effective than WW, implying a RR of 0.82 . We calibrated the transition probability of developing metastases prior to treatment under AS on the basis of the RR of PC mortality after 15 years of 0.81 and the other model parameters. This was based on the assumptions that the additional risk of PC death under AS is constituted by silent progression to metastatic disease and that metastatic $\mathrm{PC}$ is a state of terminal illness

Table 6 Out-patient costs of radiotherapy

\begin{tabular}{lcccc}
\hline Item & EBM* & $\begin{array}{c}\text { Quantity } \\
\text { p.a }\end{array}$ & Price/unit $(\boldsymbol{\epsilon})$ & $\begin{array}{c}\text { Total costs } \\
\text { p.a. }(\boldsymbol{\epsilon})\end{array}$ \\
\hline Consultation fee & 25011 & 1 & 61.86 & 61.86 \\
CT Planning & 34360 & 1 & 38.38 & 38.38 \\
Radiation plans & 25342 & 2 & 247.44 & 247.44 \\
Lump sum/radiation & 40840 & 15 & 140 & 2100 \\
field & & & & \\
Radiation & 25321 & 40 & 35.22 & 1408.93 \\
>2 fields & 25322 & 40 & 6.48 & 259.36 \\
3D-planning & 25232 & 40 & 9.46 & 378.52 \\
Sum & & & & $\mathbf{4 7 4 1 . 9 2}$ \\
\hline
\end{tabular}

*EBM = 'Einheitlicher Bewertungsmaßstab', i.e. position in the catalogue of reimbursed out-patient services.
$[4,22,44]$. Background mortality was based on the life table of the German Federal Statistical Office 2011 [2].

\section{State transition probabilities}

We identified a recent systematic review and metaanalysis of studies comparing the benefits and harms of AS and PE for the population in question as best available evidence [45]. If necessary, annual probabilities were translated into quarter-yearly probabilities via conversion to rates [46]. Transition probabilities from short

Table 7 Costs of managing erectile dysfunction

\begin{tabular}{lcccc}
\hline Item & EBM & $\begin{array}{c}\text { Quantity } \\
\text { p.a }\end{array}$ & $\begin{array}{c}\text { Price/unit } \\
(€)\end{array}$ & $\begin{array}{c}\text { Total costs } \\
\text { p.a. }(€)\end{array}$ \\
\hline
\end{tabular}

Treatment of

symptoms

Out-patient

Specialist practitioner

$\begin{array}{lcccc}\text { Consultation fee } & 1436 & 1 & 1.75 & 1.75 \\ \text { Treatment fee > 60 yrs } & 26212 & 1 & 21.20 & 21.20 \\ \text { Insuree lump sum } & 1320 & 1 & 9.11 & 9.11 \\ \text { General practitioner } & & & & \\ \text { Consultation fee } & 1436 & 2 & 1.75 & 3.50 \\ \text { Treatment fee > 60 yrs } & 3112 & 2 & 35.75 & 71.50 \\ \text { Insuree lump sum } & 3111 & 2 & 15.77 & 31.54 \\ \text { Remedies and aids* } & & & & \\ \text { Sildenafil } & & 8.75 & 44 & 385 \\ \text { Cavernous injection } & & 2.5 & 36.62 & 91.55 \\ \text { (SKAT, MUSE) } & & 2.5 & 33.19 & 82.98 \\ \text { Vacuum pump } & & 0.05 & 301.76 & 2.66 \\ \text { Ring } & & 4 & 17 & 68.00 \\ \text { Sum } & & & & \mathbf{7 6 8 . 8 0}\end{array}$

*not covered by statutory health insurance (out of pocket). 
Table 8 Costs of managing incontinence

\begin{tabular}{lccc}
\hline Item & $\begin{array}{c}\text { Quantity } \\
\text { p.a }\end{array}$ & Price/unit $(\boldsymbol{\epsilon})$ & $\begin{array}{c}\text { Total costs } \\
\text { p.a. }(\boldsymbol{\epsilon})\end{array}$ \\
\hline Treatment of symptoms & & & \\
Out-patient & & & \\
Specialist practitioner & 1 & 1.75 & 1.75 \\
Consultation fee & 1 & 21.20 & 21.20 \\
Treatment fee > 60 yrs & 1 & 9.11 & 9.11 \\
Insuree lump sum & & & \\
General practitioner & 2 & 1.75 & 3.50 \\
Consultation fee & 2 & 35.75 & 71.50 \\
Treatment fee > 60 yrs & 2 & 15.77 & 31.54 \\
Insuree lump sum & & & \\
Remedies and aids & 983 & 0.36 & 350.53 \\
Pads & 19 & 0.56 & 10.3 \\
Diapers (20 $\times 20)$ & 0.95 & 10 & 9.5 \\
Net trousers for pads/diapers & 12 & 15 & 180 \\
Physiotherapy (Pelvic floor) & 0.6 & 21.18 & 12.7 \\
Balloon catheter & 6.1 & 2.51 & 15.3 \\
Bed bag sterile & 6.1 & 4.51 & 27.4 \\
Leg bag sterile & & & $\mathbf{7 4 4 . 3 4}$ \\
Sum & & &
\end{tabular}

Table 9 Costs of managing metastatic disease

Quantity p.a Price/unit (€) Total costs

p.a. $(€)$

\begin{tabular}{|c|c|c|c|}
\hline \multicolumn{4}{|l|}{ Responsive } \\
\hline \multicolumn{4}{|l|}{ Out-patient } \\
\hline Specialist practitioner & 4 & See above & 128.28 \\
\hline \multicolumn{4}{|l|}{ Medication } \\
\hline LHRH Agonist leuprorelin & 4 & 415 & 1,660 \\
\hline \multicolumn{4}{|l|}{ Refractory } \\
\hline \multicolumn{4}{|l|}{ Medication } \\
\hline Docetaxel & 17.3 & 1768 & $30,645.3$ \\
\hline Prednisolon & 0.87 & 10.6 & 9.2 \\
\hline \multicolumn{4}{|l|}{ Bone metastases } \\
\hline \multicolumn{4}{|l|}{ Out-patient } \\
\hline Radiation & 14 & See Table 5 & $1,484.06$ \\
\hline \multicolumn{4}{|l|}{ In-patient } \\
\hline Bone scan & 0.7 & 1629.65 & $1,140.76$ \\
\hline \multicolumn{4}{|l|}{ Medication } \\
\hline Zoledron acid & 12 & 367.98 & $4,415.76$ \\
\hline
\end{tabular}

LHRH = Luteinizing Hormone-Releasing Hormone. to long term $\mathrm{AE}$ could be calculated from the quotient of the probabilities of long term $\mathrm{AE}$ and short term $\mathrm{AE}$, i.e. $\mathrm{P}($ transition short term to long term $\mathrm{AE})=\mathrm{P}(\mathrm{AE}$ long term) $/ \mathrm{P}(\mathrm{AE}$ short term). For transitions to states with combined $\mathrm{AE}$, statistical independence was presumed except in the case of IC. Here, it was assumed that $80 \%$ of patients experiencing IC would also experience ED. For an overview of transition probabilities, please refer to Table 10.

\section{Analysis \\ Sensitivity analysis}

Univariate sensitivity analysis was conducted for all parameters to analyse their isolated impact on costeffectiveness. For transition probabilities and utilities, input values were varied within the 95\% confidence interval. The probability of developing metastases under AS was varied between assuming no difference in disease related mortality compared with $P E$ (i.e. $R R=1$ ) and the full treatment effect found in the SPCG trial (i.e. RR $=0.62$ ). Costs for in-patient treatments were varied by running the model with DRG rates resulting from maximum and minimum days of hospitalisation resulting from treatment. All other cost variables were tested by assuming half and double the central estimate. The 10 variables with the highest impact on model uncertainty are presented in a tornado diagram (Figure 3). Given that there exists no explicit cost-effectiveness threshold for Germany, net benefits were calculated with the frequently quoted willingness to pay (WTP) threshold of $€ 50,000$, which was chosen for illustration only to incorporate impacts on both effects and costs $[49,50]$. Based on the tornado analysis, we report threshold values for variables that changed strategy rankings. Key assumptions of the model were varied to test the robustness of the base case results. First, we considered alternative time horizons of 5, 15 and 30 years. Furthermore, we tested the influence of applying alternative discount rates, where both costs and benefits were discounted at the same rate. Following German recommendations, the discount rate was varied between using values of $0 \%, 5 \%$, $7 \%$ and $10 \%[19,51]$.

\section{Probabilistic analysis}

Multivariate probabilistic sensitivity analysis was conducted to assess overall model uncertainty. For this purpose, values were simultaneously and randomly drawn in second order Monte Carlo simulation. Beta distributions were adopted for probabilities and utilities and gamma distributions for costs. The distribution parameters were derived from the model parameter's expected value and standard error (Tables 1, 10 and 11). In the case of costs, the standard error (SE) was calculated based on the range applied for deterministic sensitivity 
Table 10 Transition probabilities

\begin{tabular}{|c|c|c|c|c|}
\hline State & Event & Expected value & SE & Source* \\
\hline \multirow[t]{7}{*}{ AS } & Progression of Gleason Score & 0.0263 & 0.007 & \\
\hline & Other Progression (DRE/PSA) & 0.0268 & 0.007 & \\
\hline & Choosing treatment & 0.018 & 0.005 & \\
\hline & Developing metastatic prostate cancer under active surveillance & 0.0023 & 0.000425 & Bill-Axelson [7]; own calculation \\
\hline & Infection due to biopsy & 0.02 & 0.0075 & Cambell-Walsh Urology \\
\hline & Develop benign prostate hyperplasia & Age dependent & & Andersson 2004 [48] \\
\hline & Transurethral resection of the prostate due to benign prostate hyperplasia & 0.000462 & - & Andersson 2004; own calculation \\
\hline \multirow[t]{3}{*}{ Treatment } & Perioperative death & 0.0044 & 0.00001 & \\
\hline & Major complication during surgery & 0.0472 & 0.0168 & \\
\hline & Urethral stricture & 0.0344 & 0.002 & \\
\hline \multirow[t]{9}{*}{ Post PE } & Incontinence and erectile dysfunction short term & 0.37 & 0.0467 & \\
\hline & Erectile dysfunction short term & 0.39 & 0.0384 & \\
\hline & Incontinence short term & 0.09 & 0.0113 & \\
\hline & Keep incontinence and erectile dysfunction long term & 0.27 & 0.0338 & \\
\hline & Keep incontinence long term & 0.28 & 0.035 & \\
\hline & Keep erectile dysfunction long term & 0.89 & 0.0831 & \\
\hline & Disease recurrence & 0.00875 & 0.0032 & \\
\hline & Progression from recurrence to metastatic disease & 0.0127 & 0.0047 & Horwitz 2005 [49] \\
\hline & $\begin{array}{l}\text { Death due to prostate cancer after development of metastatic } \\
\text { state during hormonal therapy }\end{array}$ & 0.022 & 0.0225 & Alibhai [44] \\
\hline \multirow[t]{7}{*}{ Post RT } & Incontinence short term & 0.3 & 0.0835 & \\
\hline & Bowel problems short term & 0.18 & 0.0506 & \\
\hline & Bowel problems and incontinence short term & 0.054 & 0.0068 & \\
\hline & Keep incontinence long term & 0.16 & 0.02 & \\
\hline & Keep bowel problems long term & 0.152 & 0.019 & \\
\hline & Erectile dysfunction long term & 0.064 & 0.016 & \\
\hline & Keep incontinence and bowel problems long term & 0.148 & 0.0148 & \\
\hline IC & Sphincter/sling surgery & 0.05 & 0.0075 & \\
\hline ED & Prosthesis surgery & 0.02 & 0.0003 & \\
\hline Death & Death due to other reasons & Age dependent & - & \\
\hline
\end{tabular}

*If not stated otherwise: [45].

$\mathrm{AS}=$ Active Surveillance, $\mathrm{ED}=$ Erectile Dysfunction.

DRE = Digital Rectal Examination, IC = Incontinence.

PSA = Prostate Specific Antigen

$\mathrm{PE}=$ Prostatectomy.

$\mathrm{RT}=$ Radiotherapy.

analysis as follows: $\mathrm{SE}=($ Max value - Min value $) / 4$. The probabilistic sensitivity analysis was based on 1,000 replications, and the results are presented as a costeffectiveness acceptability curve (CEAC) and as a scatter plot on the cost-effectiveness plane.

\section{Validation}

For the sake of cross validation a structured literature search was performed in the databases PubMed, NHS Centre for Reviews and Dissemination as well as Google Scholar to compare our results with existing economic cost-utility models of AS and PE. First we looked for existing reviews of economic evaluations using the (Mesh-) terms 'review', 'prostatic neoplasm' and 'economics'. After screening titles and abstracts for the terms 'model,' 'evaluation,' 'cost(s) ,' 'utility,' 'quality of life,' 'effectiveness' and 'benefit' we analysed full texts. In a second step we searched for economic evaluations using the (Mesh-) terms 'prostatic neoplasm' and 'economics'. Face validity of the model structure and major model assumptions was undertaken within our modelling team (FK, BS) and with our clinical expert (RW). Furthermore, we 


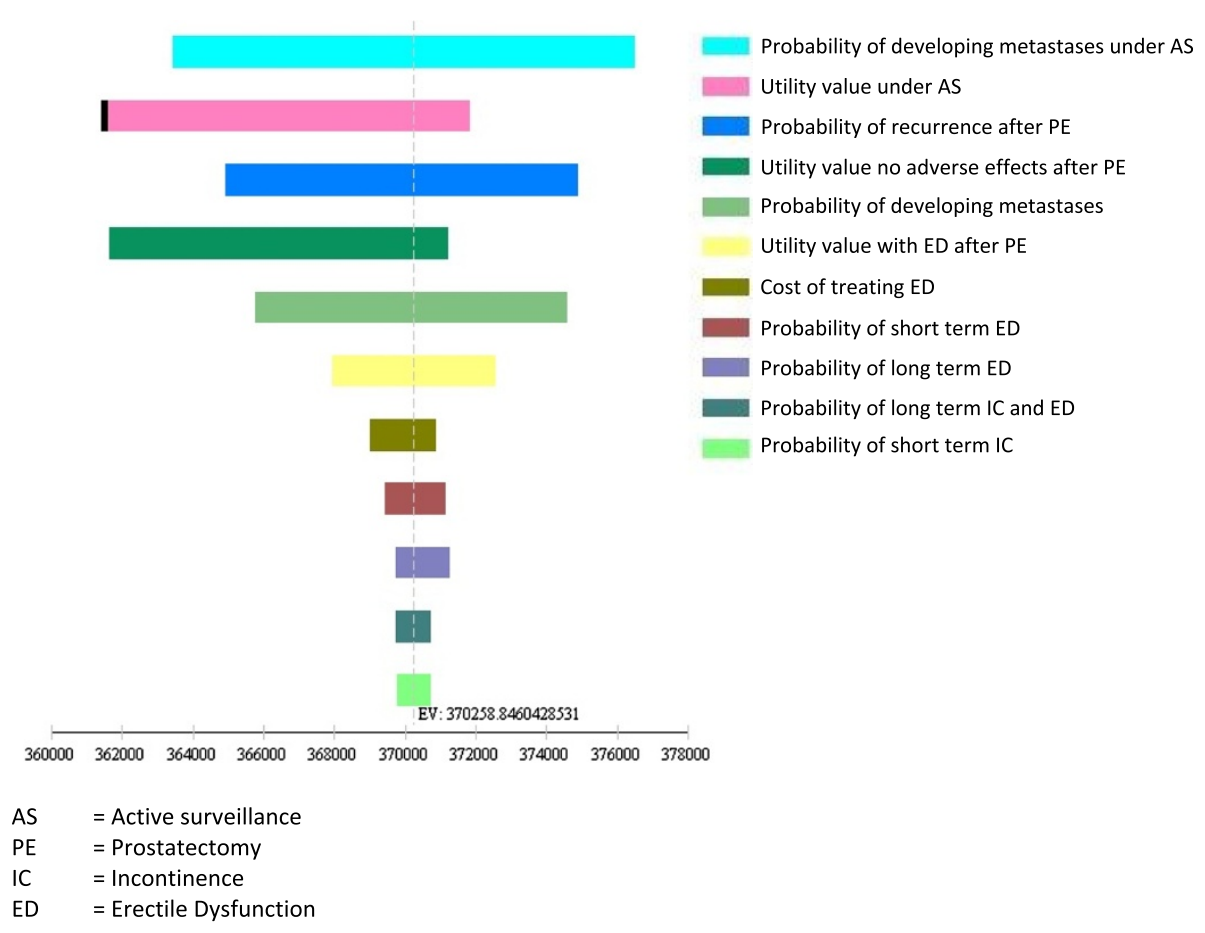

Figure 3 Tornado diagram (Net Benefits in $€$ ).

compared model results with clinical data from the American PIVOT trial for the purpose of external validation.

\section{Results}

\section{Base case}

Expected, discounted life expectancy was 12.07 years under AS and 12.15 years with initial surgery if not

Table 11 Parameters for probabilistic sensitivity analysis of costs

\begin{tabular}{lll}
\hline Costs item & $\begin{array}{l}\text { Expected } \\
\text { value in } €^{*}\end{array}$ & SE \\
\hline Prostatectomy & 6,886 & 843.75 \\
Conservative treatment of incontinence & 186 & 23.25 \\
Conservative treatment of erectile dysfunction & 192 & 24.03 \\
Radiotherapy & 4,742 & 592.75 \\
Treatment of metastases & 447 & 55.88 \\
Surgical treatment of urosepsis & 3,796 & 384.50 \\
Treatment prostate hyperplasia & 108 & 13.50 \\
Transurethral resection of the prostate & 3,769 & 86.25 \\
Surgical treatment of incontinence & 2,292 & 286.50 \\
Surgical treatment of erectile dysfunction & 10,238 & $1,279.75$ \\
Treatment of refractory metastases & $7,663.75$ & 957.97 \\
Treatment of bone metastases & $1,760.25$ & 220.03 \\
\hline
\end{tabular}

${ }^{*}$ Quarter yearly except for surgical procedures. adjusted for quality of life. This was associated with discounted costs of $€ 16,468$ for PE and $€ 9,585$ for AS. Treatment with PE therefore generated an additional 0.08 life years and caused additional costs of $€ 6,883$, corresponding to an incremental cost-effectiveness ratio (ICER) of $€ 96,420$ /life year gained. Some $48 \%$ or $€ 7,935$ of overall costs were caused by initial treatment in the PE arm. Treatment costs resulting from PE or RT amounted to $€ 3,463$ in the AS arm, accounting for $36 \%$ of all costs. Costs for AS only amounted to $€ 2,178$, making up $22 \%$ of total costs. After adjusting for quality of life, effects decreased to 7.60 QALYs under AS and 7.56 QALYs with initial surgery. So AS dominated initial treatment, causing higher effects $(+0.04)$ and lower costs $(-€ 6,883)$ in the base case. The lifetime risk of PC death was $11.49 \%$ under AS and $10.92 \%$ in the PE cohort.

\section{Sensitivity analysis}

AS dominated initial surgery in all time perspectives. Because the average health of the population as well as the share of people under AS decreases over time, the benefit of avoiding postoperative $\mathrm{AE}$ is most influential in the first years after diagnosis. As the share of people under AS decreases and PC mortality increases, this effect is temporarily compensated for between years 3 and 15 . After this, rapidly increasing other cause mortality limits the relative influence of additional PC mortality, which correspondingly puts more weight on patients still under AS. With increasing values for the discount rate, the 
Table 12 Results of sensitivity analysis

\begin{tabular}{|c|c|c|c|c|c|c|c|c|}
\hline \multirow[t]{2}{*}{ Parameter } & \multirow[t]{2}{*}{ Value } & \multicolumn{3}{|c|}{ Costs $(€)$} & \multicolumn{3}{|c|}{ Effects (QALY) } & \multirow[t]{2}{*}{ ICER (€/QALY) } \\
\hline & & $\mathrm{PE}$ & AS & Difference & $\mathrm{PE}$ & AS & Difference & \\
\hline \multirow[t]{3}{*}{ Base case } & Time horizon 5 & 11,355 & 4,080 & $-7,275$ & 2.971 & 3.019 & -0.048 & Dominated \\
\hline & Time horizon 15 & 15,011 & 8,263 & $-6,748$ & 6.454 & 6.467 & -0.013 & Dominated \\
\hline & Time horizon 30 & 16,444 & 9,564 & $-6,880$ & 7.545 & 7.567 & -0.022 & Dominated \\
\hline \multirow[t]{4}{*}{ Discount rate } & $0 \%$ & 19,013 & 12,201 & $-6,811$ & 9.778 & 9.800 & -0.022 & Dominated \\
\hline & $5 \%$ & 15,291 & 8,346 & $-6,945$ & 6.525 & 6.549 & -0.025 & Dominated \\
\hline & $7 \%$ & 14,386 & 7,376 & $-7,010$ & 5.713 & 5.739 & -0.027 & Dominated \\
\hline & $10 \%$ & 13,376 & 6,270 & $-7,106$ & 4.794 & 4.824 & -0.029 & Dominated \\
\hline
\end{tabular}

amount of QALY gains and cost savings decreased, but AS remained the dominant strategy for all discount rates between $0 \%$ and $10 \%$ (Table 12). Figure 3 depicts the results of the univariate sensitivity analyses in the form of a tornado diagram that displays the effect of the uncertainty associated with individual parameter values on the net monetary benefits of AS for a WTP of $€ 50,000$. The utility weight for patients under AS and the probability of developing metastases under AS have the highest impact on model results. Probabilities of recurrence after PE and developing metastases as well as the utility weight for no $\mathrm{AE}$ after PE are almost equally influential variables. Threshold analysis revealed that seven of the most influential variables changed the strategy ranking when varied within their 95\% confidence intervals (Table 13). The probability of developing metastases under AS proved to be particularly influential. The strategy ranking changed at a threshold value of $\mathrm{P}=0.0025$

Table 13 Results of threshold analysis

\begin{tabular}{lcc}
\hline Variable & $\begin{array}{c}\text { Base case } \\
\text { value }\end{array}$ & $\begin{array}{c}\text { Threshold } \\
\text { value }\end{array}$ \\
\hline Probability of developing metastases under AS & 0.0023 & 0.0025 \\
Probability of PC recurrence after PE & 0.00875 & 0.00772 \\
Utility value after PE with no adverse effects & 0.99 & 1 \\
Utility value under AS & 0.99 & 0.98 \\
Probability of developing metastases after & 0.0127 & 0.0113 \\
recurrence & & 0.91 \\
Utility value after PE with ED & 0.89 & None \\
Costs of treatment of ED & 768.8 & 0.73 \\
Probability of short term ED & 0.77 & 0.79 \\
Probability of long term ED & 0.89 & None \\
Probability of long term ED and IC & 0.27 & None \\
\hline Probability of short term IC & 0.47 &
\end{tabular}

AS = Active Surveillance.

$\mathrm{PC}=$ Prostate Cancer.

$\mathrm{PE}=$ Prostatectomy.

$\mathrm{IC}=$ Incontinence.

$\mathrm{ED}=$ Erectile Dysfunction . corresponding to a RR of prostate cancer death of 0.76 . Additionally we performed a threshold analysis for the proportion of patients under AS crossing over to curative treatment. This proportion is driven by the probability of disease progressing for any reason (i.e. Gleason score or DRE + PSA) and men electing treatment without signs of progression. In the base case this corresponds to an annual crossover probability of $\mathrm{P}_{\text {crossover }}=$ 0.071 and $61 \%$ of patients under AS being treated. PE strategy became more effective than AS at a threshold value of $\mathrm{P}_{\text {crossover }}=0.149$ with $81 \%$ of AS patients crossing over to radical treatment.

\section{Probabilistic sensitivity analysis}

Probabilistic analysis resulted in mean discounted costs of $€ 16,415$ (95\% CI $€ 13,664, € 19,339$ ) for PE and $€ 9,564$ (95\% CI $€ 8,535, € 10,735)$ for the AS strategy. Mean QALYs amounted to 7.58 (95\% CI 7.06, 7.93) and 7.60 (95\% CI 7.07, 7.83) for PE and AS respectively. Figure 4 shows a scatter plot of ICERs for 1,000 repetitions. AS was the more effective strategy in $56 \%$ of all realisations, and it was always associated with lower costs. Figure 5 shows the corresponding CEAC for AS. Even at very high WTP thresholds, the probability of AS being the more effective strategy is more than $50 \%$.

\section{Validation}

Two decision-analytic models could be identified that compared the effectiveness of AS and PE for the treatment of early stage prostate cancer in terms of QALYs generated [29,33], and one other cost-utility study was found [52]. All these studies were undertaken from an American perspective. The models published by Hayes et al. both indicate that more QALYs are generated under AS than with initial PE (11.07 vs. 10.23 and 8.85 vs. 7.95) [29,52]. The study by Liu et al. reports a smaller QALY advantage for a comparable cohort of men. In their study, AS was associated with an additional 0.05 QALYs [33]. The smaller difference in QALYs is likely to be related to the fact that Hayes et al. assume that utility 


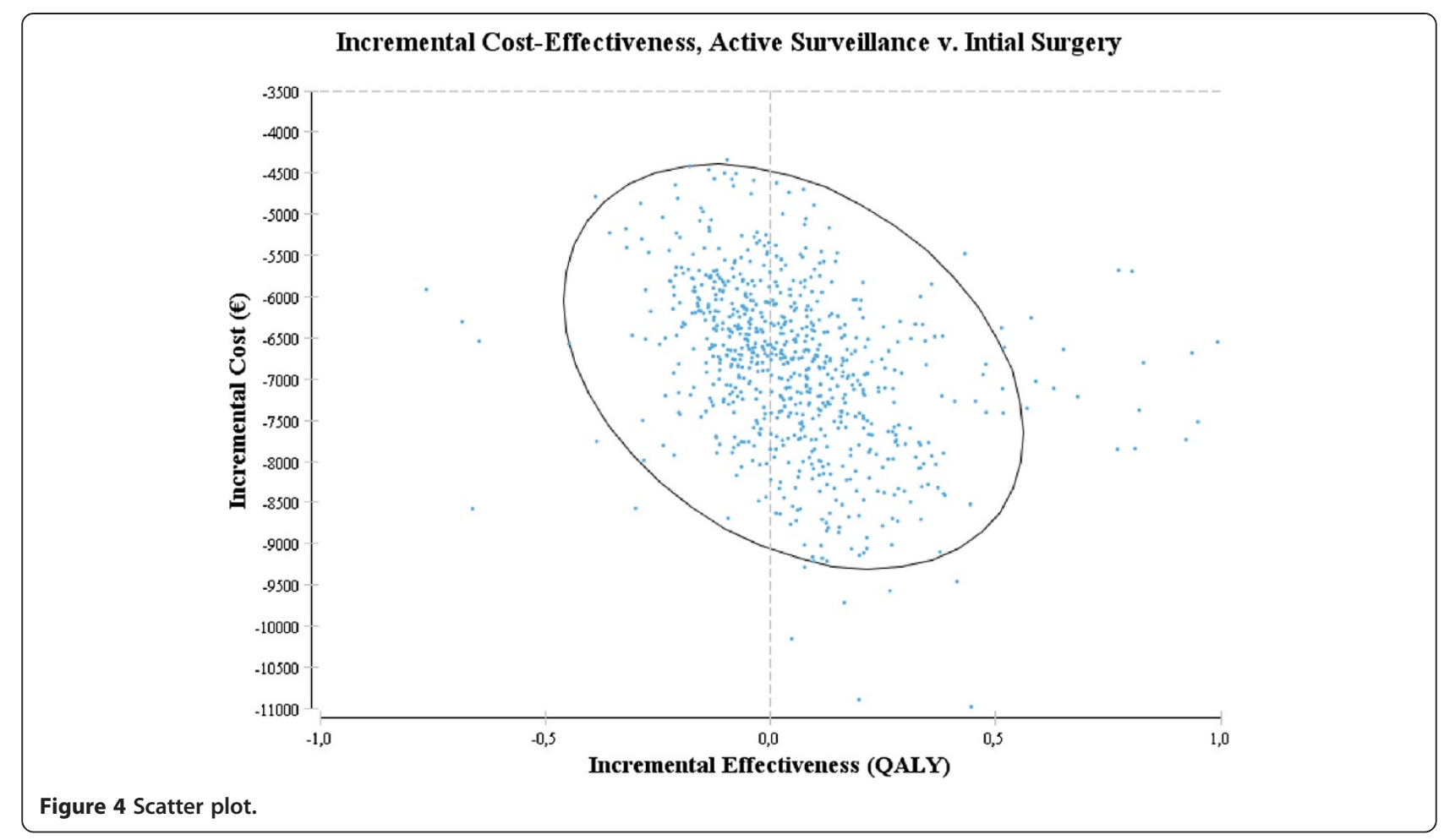

under AS is higher than after PE with no adverse effects. Liu et al. assume equal utility in both states. Our study reports a smaller overall amount of QALYs because the age related decline in quality of life is also considered. The only cost-utility study identified also found AS to be a cost-saving strategy from the perspective of US Medicare [52]. This corresponds to a recent study by Keegan et al. showing that AS is a cost-saving treatment option when compared with immediate treatment in the context of the US healthcare system [53]. Face validation resulted in model adaptations with respect to development and treatment of AEs, length of transition cycles as well as assumptions concerning resource utilisation. For the sake of external validation, we ran the model with the $\mathrm{RR}$ of PC death derived from the PIVOT trial. Ceteris paribus this resulted in the same strategy ranking with additional 0.01 QALYs gained in the AS arm (7.61).

\section{Discussion}

We present the first cost-utility study assessing the costeffectiveness of AS and PE in a European context. Our analysis demonstrated that AS is a cost-saving treatment strategy for men aged 65 years with low risk, early stage carcinoma. AS generates more QALYs at lower costs

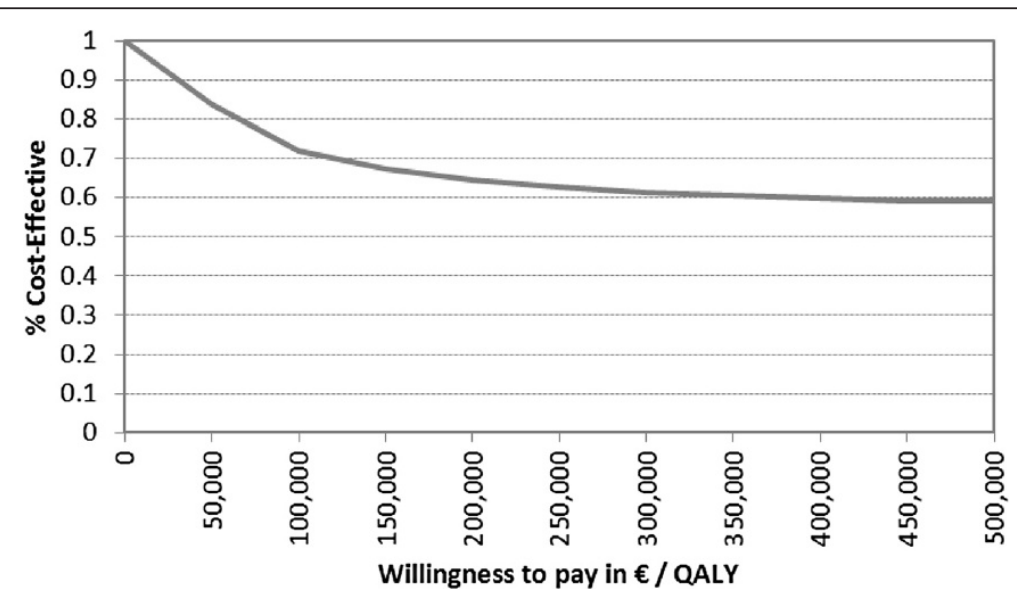

Figure 5 Cost-effectiveness acceptability curve for active surveillance. 
than treatment with PE in this cohort. The difference in life expectancy was small as other cause mortality accounted for most deaths and limited the influence of treatment specific differences of PC death. Sensitivity to changes in the discount rate and time horizons was low and did not change strategy rankings.

Despite these results, PE is currently widely applied. As the calculation of costs shows, this may be because the current reimbursement rates in Germany set incentives in favour of PE rather than the AS strategy. For example, the restricted ambulatory reimbursement for AS conflicts with the increased patient need for information and counselling. Also, hospitals cannot charge for preventive services and patients are not charged copayments if they choose the more costly service.

The wide spread of effectiveness results shown in the scatter plot (Figure 4) illustrates that the results are associated with considerable uncertainty surrounding key effectiveness and outcome parameters. Sensitivity analysis revealed that the results are highly sensitive to varying the probability of developing metastases under AS. This reflects the uncertainty concerning the precision of early stage diagnosis and the associated uncertainty in comparative effectiveness between AS and PE. The risk of under-staging, i.e. wrongly diagnosing an aggressive tumour as low risk, due to the limited predictive power of current diagnostic tools is a challenge for current urological research [54]. It has been shown that more than $25 \%$ of tumours may be wrongly diagnosed as insignificant in clinical practice $[55,56]$. Better diagnostic methods for identifying particularly aggressive tumours, e.g. by new molecular markers, analysis of DNA ploidy or CYP3A4 genotype [57], would increase the effectiveness of AS on account of the reduced number of PC deaths due to under staging [54].

Given the currently available staging methods, despite identical clinical parameters, the optimal therapy recommendation may differ depending on the patient's tradeoff between quantity and quality of life and personal risk appetite [32]. Some patients may prefer the avoidance of AEs at the cost of increased risk of dying from PC. Others might not be willing to carry this risk and, at the same time, not consider AEs such as ED as a significant loss of quality of life. For such patients, PE may be a treatment strategy that is considered comparatively expensive but still cost-effective by a number of health care payers. This is highlighted by the fact that, if the lifetime spent in different health states is not adjusted for quality of life, PE is associated with an ICER of $€ 96,420 /$ QALY compared with AS. Also, postoperative rates of IC and ED - the main drivers of QALY advantage under AS-may differ considerably depending on the experience of the surgeon and the overall PE volume of the institution $[58,59]$.
Although consideration of individual patient preference and local setting is an important issue in clinical practice, our study aimed to investigate the cost-utility of AS from a broader health care systems perspective. One of the strengths of our model is the use of age adjusted, population specific utilities in addition to health state specific utility weights. Although this methodology has been demanded by health economists, it is hardly applied in health economic evaluations [60]. Utilities can have a big influence on model results, and disregarding the utility level of the general population overestimates the amount of QALYs generated. Especially in an elderly study population, the effects of age dependent decline in mean utility can significantly influence QALY gains.

Our study is the first evaluation that systematically includes costs for PC management in a European country in the decision analysis. Prices for health services in European countries can differ substantially from those in the US and affect the transferability of results of economic evaluations [61]. The costs quoted for the PSA test in the US evaluation, for example, were almost $80 \%$ higher than in Germany, and the costs for PE were over $20 \%$ higher (based on an exchange rate of $\$ 0.75 / €$ ).

\section{Limitations}

A limitation of this study is the restricted quality of evidence concerning disease specific outcomes of treatments. We based our study on the RR of dying from PC from an RCT comparing WW with PE. WW describes a different strategy from AS and is more likely to favour $\mathrm{PE}$ as a treatment option. We tried to take account of this by conservatively assuming only half the treatment benefit being maintained under AS and performing wide range sensitivity analysis. We did not include all possible treatment options in our model. There is no conclusive comparative evidence available for alternative treatment options such as brachytherapy or intensity modulated radiation therapy $[20,62]$. Finally, we assumed that surgical treatment of benign prostate syndrome under AS did not affect the probability of disease progression, which might not be realistic. However, as a reduction in the probability of disease progression would favour AS, this corresponds with our conservative modelling approach.

\section{Conclusion}

The model results indicate that the difference in overall health outcomes between AS and PE is small. On average, approximately one month of life is gained by having immediate surgery; when QALYs are considered, about two additional weeks of life spent in perfect health can be gained by choosing AS. Given the cost difference, the cost-utility analysis replaces the clinical ambiguity with a more solid conclusion that AS may offer better value for money, given the assumptions and perspective of this 
analysis. In conflict with these results, current reimbursement practise in Germany sets incentives in favour of PE rather than the AS strategy. This study may serve as a starting point to analyse the costs and incentives associated with existing reimbursement patterns in comparison with alternative arrangements.

The model results are subject to substantial uncertainty so that they must be handled with caution. This confirms the importance of ongoing clinical studies, such as the HAROW study in Germany [63] and the German RCT PREFERE [64], that will improve the evidence base in future years. The model needs to be updated as soon as new data from these studies are available. Appropriate staging and risk prediction, which allows the differentiation of high and low risk tumours, plays an important role in decisions about the optimal clinical strategy. Therefore, further research is needed to allow for a better stratification of invasive interventions to high risk patients. This cost-utility analysis can be used for early evaluation of the potential impact of different newly evolving diagnostic strategies on the costs and effects of PC management to inform further research and development [65].

This study revealed that whether PE is considered effective depends not only on clinical data but also on patient preferences about the role of quality of life in decision making. Existing evaluations are typically based on estimates of mean utility gains, which are insensitive to this aspect of benefit. Further research is necessary to better determine the appropriate role of preferences in existing evaluation frameworks. Finally, there is a need for further research on decision aids that make such information accessible to PC patients. Traditional approaches to informing the decision have been shown to understate the importance of postoperative AEs [66]. Ideally, these aspects could be combined so that an analysis of existing incentives and the integration of information from improved biomarker based risk prediction, valuations of health states and cost-effectiveness would lead to new models of fully personalised and costeffective prostate cancer care.

\section{Competing interests}

The authors declare that they have no financial or non-financial competing interests.

\section{Authors'contributions \\ FK programmed the model and drafted the manuscript. RW developed the model structure and provided medical expertise concerning various aspect of urologic health care provision. BS provided statistical expertise for parameter synthesis and analysis. WR conceived the study, and participated in its design and coordination. All authors read and approved the final manuscript.}

\section{Acknowledgements}

I am indebted to Ernst Koerber and Alina Brandes for valuable discussions and comments on earlier versions of this paper and to Matthias Hunger for supporting the analysis of quality of life data. Heather Hynd proofread the final article.

This research is carried out on behalf of Helmholtz Zentrum München German Research Center for Environmental Health (HMGU). The HMGU is an independent organization funded by the German and Bavarian government. The authors FK, BS and WR are employees of the HMGU. The research was supported by a grant from the German Federal Ministry of Education and Research (BMBF, grant number 01KQ0902V). Neither the HGMU nor the BMBF had any influence on design, collection, analysis, and interpretation of data; in the writing of the manuscript; and in the decision to submit the manuscript for publication.

The author RW is employed by the Klinikum d.Universität München Urologische Klinik und Poliklinik (university hospital Munich). The university hospital Munich had no influence on design, collection, analysis, and interpretation of data; in the writing of the manuscript; and in the decision to submit the manuscript for publication.

\section{Author details}

${ }^{1}$ Institute for Health Economics and Health Care Management, Helmholtz Zentrum Munich, German Research Center for Environmental Health (GmbH), Ingolstädter Landstrasse 1, 85764 Neuherberg, Germany. ${ }^{2}$ Department of Urology, University of Munich, Marchioninistraße 15, 81377 Munich, Germany. ${ }^{3}$ Institute and Outpatient Clinic for Occupational, Social and Environmental Medicine, University of Munich, Ziemssenstraße 1, 80336 Munich, Germany.

Received: 5 October 2013 Accepted: 25 March 2014

Published: 10 April 2014

\section{References}

1. Jemal A, Bray F, Center MM, Ferlay J, Ward E, Forman D: Global cancer statistics. CA Cancer J Clin 2011, 61(2):69-90.

2. Statistisches Bundesamt: Statistisches Jahrbuch 2011 für die Bundesrepublik Deutschland [Statistical Yearbook 2011 for the Federal Republic of Germany]. Wiesbaden: Federal Statistical Office; 2011.

3. Moul JW, Wu H, Sun L, McLeod DG, Amling C, Lance R, Kusuda L, Donahue T, Foley J, Chung A, Sexton W, Soderdahl D, Rich NM: Epidemiology of radical prostatectomy for localized prostate cancer in the era of prostate-specific antigen: an overview of the Department of Defense Center for Prostate Disease Research national database. Surgery 2002, 132(2):213-219.

4. Wein AJ, Kavoussi LR, Novick AC, Partin AW, Peters CA: Campbell-Walsh Urology. 10th edition. Philadelphia: Elsevier Health Sciences; 2011.

5. Interdisziplinäre Leitlinie der Qualität S3 zur Früherkennung, Diagnose und Therapie der verschiedenen Stadien des Prostatakarzinoms. http://www. awmf.org/uploads/tx_szleitlinien/043-022OLI_S3_Prostatakarzinom_2011.pdf.

6. Schmedders $M$, Janatzek S, Zimmer B: Benefit assessment by the Federal Joint Committee: assessment of treatment strategies for low risk prostate cancer. Urologe A 2011, 50(8):938-943.

7. Bill-Axelson A, Holmberg L, Ruutu M, Garmo H, Stark JR, Busch C, Nordling S, Haggman M, Andersson SO, Bratell S, Spångberg A, Palmgren J, Steineck G, Adami HO, Johansson JE, SPCG-4 Investigators: Radical prostatectomy versus watchful waiting in early prostate cancer. N Engl J Med 2011, 364(18):1708-1717.

8. Gronberg H: Prostate cancer epidemiology. Lancet 2003, 361(9360):859-864.

9. Popiolek M, Rider JR, Andrén O, Andersson S-O, Holmberg L, Adami H-O, Johansson J-E: Natural history of early, localized prostate cancer: a final report from three decades of follow-up. Eur Urol 2013, 63(3):428-435.

10. Klotz L: Active surveillance with selective delayed intervention for favorable risk prostate cancer. Urol Oncol 2006, 24(1):46-50.

11. Heidenreich A, Bellmunt J, Bolla M, Joniau S, Mason M, Matveev V, Mottet $\mathrm{N}$ Schmid HP, van der Kwast T, Wiegel T, Zattoni F, European Association of Urology: EAU guidelines on prostate cancer: part 1: screening, diagnosis, and treatment of clinically localised disease. Eur Urol 2011, 59(1):61-71.

12. Boorjian SA, Eastham JA, Graefen M, Guillonneau B, Karnes RJ, Moul JW, Schaeffer EM, Stief C, Zorn KC: A critical analysis of the long-term impact of radical prostatectomy on cancer control and function outcomes. Eur Urol 2012, 61(4):664-675.

13. Johansson $E$, Steineck G, Holmberg L, Johansson JE, Nyberg T, Ruutu M, Bill-Axelson A: Long-term quality-of-life outcomes after radical prostatectomy or watchful waiting: the Scandinavian prostate cancer group-4 randomised trial. Lancet Oncol 2011, 12(9):891-899. 
14. Dall'Era MA, Albertsen PC, Bangma C, Carroll PR, Carter HB, Cooperberg MR, Freedland SJ, Klotz LH, Parker C, Soloway MS: Active surveillance for prostate cancer: a systematic review of the literature. Eur Urol 2012, 62(6):976-983

15. Parker C: Active surveillance: towards a new paradigm in the management of early prostate cancer. Lancet Oncol 2004, 5(2):101-106.

16. Dahabreh IJ, Chung M, Balk EM, Yu WW, Mathew P, Lau J, Ip S: Active surveillance in men with localized prostate cancera systematic review. Ann Intern Med 2012, 156(8):582-590.

17. Xia J, Trock BJ, Cooperberg MR, Gulati R, Zeliadt SB, Gore JL, Lin DW, Carroll $\mathrm{PR}$, Carter HB, Etzioni R: Prostate cancer mortality following active surveillance versus immediate radical prostatectomy. Clin Cancer Res 2012, 18(19):5471-5478.

18. Husereau D, Drummond M, Petrou S, Carswell C, Moher D, Greenberg D, Augustovski F, Briggs AH, Mauskopf J, Loder E: Consolidated Health Economic Evaluation Reporting Standards (CHEERS)-explanation and elaboration: a report of the ISPOR health economic evaluation publication guidelines good reporting practices task force. Value Health 2013, 16(2):231-250.

19. Methods for Assessment of the Relation of Benefits to Costs in the German Statutory Health Care System. https://www.iqwig.de/en/methods/ methods_papers/health_economic_evaluation.3022.html.

20. Hummel S, Simpson EL, Hemingway P, Stevenson MD, Rees A: Intensitymodulated radiotherapy for the treatment of prostate cancer: a systematic review and economic evaluation. Health Technol Assess 2010, 14(47):1-108. iii-iv.

21. Iremashvili V, Soloway MS, Rosenberg DL, Manoharan M: Clinical and demographic characteristics associated with prostate cancer progression in patients on active surveillance. J Urol 2012, 187(5):1594-1599.

22. Dall'Era MA, Cooperberg MR, Chan JM, Davies BJ, Albertsen PC, Klotz LH, Warlick CA, Holmberg L, Bailey DE Jr, Wallace ME, Kantoff PW, Carroll PR: Active surveillance for early-stage prostate cancer: review of the current literature. Cancer 2008, 112(8):1650-1659.

23. Constantinides CA, Tyritzis SI, Skolarikos A, Liatsikos E, Zervas A, Deliveliotis $C$ : Short- and long-term complications of open radical prostatectomy according to the Clavien classification system. BJU Int 2009, 103(3):336-340.

24. Veldeman L, Madani I, Hulstaert F, De Meerleer G, Mareel M, De Neve W: Evidence behind use of intensity-modulated radiotherapy: a systematic review of comparative clinical studies. Lancet Oncol 2008, 9(4):367-375.

25. Wood S: Generalized Additive Models: An Introduction with R. Boca Raton: Taylor \& Francis; 2006.

26. Ara R, Brazier JE: Using health state utility values from the general population to approximate baselines in decision analytic models when condition-specific data are not available. Value Health 2011, 14(4):539-545.

27. Mielck A, Vogelmann M, Schweikert B, Leidl R: Health status of adults in germany: results from a representative survey using the EuroQol 5D (EQ-5D). Gesundheitswesen 2010, 72(8-9):476-486.

28. Bremner KE, Chong CA, Tomlinson G, Alibhai SM, Krahn MD: A review and meta-analysis of prostate cancer utilities. Med Decis Making 2007, 27(3):288-298

29. Hayes JH, Ollendorf DA, Pearson SD, Barry MJ, Kantoff PW, Stewart ST, Bhatnagar V, Sweeney CJ, Stahl JE, McMahon PM: Active surveillance compared with initial treatment for men with low-risk prostate cancer: a decision analysis. JAMA 2010, 304(21):2373-2380.

30. Krahn MD, Bremner KE, Alibhai SM, Ni A, Tomlinson G, Laporte A, Naglie G: A reference set of health utilities for long-term survivors of prostate cancer: population-based data from Ontario, Canada. Qual Life Res 2013, 22(10):2951-2962.

31. Stewart ST, Lenert $L$, Bhatnagar $V$, Kaplan RM: Utilities for prostate cancer health states in men aged 60 and older. Med Care 2005, 43(4):347-355.

32. Sommers BD, Beard CJ, D'Amico AV, Dahl D, Kaplan I, Richie JP, Zeckhause $\mathrm{RJ}$ : Decision analysis using individual patient preferences to determine optimal treatment for localized prostate cancer. Cancer 2007, 110(10):2210-2217.

33. Liu D, Lehmann HP, Frick KD, Carter HB: Active surveillance versus surgery for low risk prostate cancer: a clinical decision analysis. J Urol 2012, 187(4):1241-1246.

34. Kassenärztliche Bundesvereinigung. http://www.kbv.de/

35. Intitut für Entgeltsysteme im Krankenhaus. http://www.g-drg.de/cms/.

36. Research Institute of the AOK. http://wido.de/arzneimittel.html.
37. Pinkhasov GI, Lin YK, Palmerola R, Smith P, Mahon F, Kaag MG, Dagen JE, Harpster LE, Reese CT, Raman JD: Complications following prostate needle biopsy requiring hospital admission or emergency department visits experience from 1000 consecutive cases. BJU Int 2012, 110(3):369-374.

38. Wilson EC, McKeen ES, Scuffham PA, Brown MC, Wylie K, Hackett G: The cost to the United Kingdom National Health Service of managing erectile dysfunction: the impact of sildenafil and prescribing restrictions. Pharmacoecon 2002, 20(13):879-889.

39. Groot MT, Boeken Kruger CG, Pelger RC, Uyl-de Groot CA: Costs of prostate cancer, metastatic to the bone, in the Netherlands. Eur Urol 2003, 43(3):226-232.

40. Wilt TJ, Brawer MK, Jones KM, Barry MJ, Aronson WJ, Fox S, Gingrich JR, Wei JT, Gilhooly P, Grob BM, Nsouli I, lyer P, Cartagena R, Snider G, Roehrborn C, Sharifi R, Blank W, Pandya P, Andriole GL, Culkin D, Wheeler T, Prostate Cancer Intervention versus Observation Trial (PIVOT) Study Group: Radical prostatectomy versus observation for localized prostate cancer. N Engl J Med 2012, 367(3):203-213.

41. Bock CH, Schwartz AG, Ruterbusch JJ, Levin AM, Neslund-Dudas C, Land SJ, Wenzlaff AS, Reich D, McKeigue P, Chen W, Heath El, Powell IJ, Kittles RA, Rybicki BA: Results from a prostate cancer admixture mapping study in African-American men. Hum Genet 2009, 126(5):637-642.

42. Miller DC, Zheng SL, Dunn RL, Sarma AV, Montie JE, Lange EM, Meyers DA, $\mathrm{Xu} J$, Cooney KA: Germ-line mutations of the macrophage scavenger receptor 1 gene: association with prostate cancer risk in AfricanAmerican men. Cancer Res 2003, 63(13):3486-3489.

43. Holmberg L, Bill-Axelson A, Helgesen F, Salo JO, Folmerz P, Haggman M, Andersson SO, Spangberg A, Busch C, Nordling S, Palmgren J, Adami HO, Johansson JE, Norlén BJ, Scandinavian Prostatic Cancer Group Study Number 4: A randomized trial comparing radical prostatectomy with watchful waiting in early prostate cancer. N Engl J Med 2002, 347(11):781-789.

44. Alibhai SM, Naglie G, Nam R, Trachtenberg J, Krahn MD: Do older men benefit from curative therapy of localized prostate cancer? J Clin Oncol 2003, 21(17):3318-3327.

45. Active Surveillance and Radical Prostatectomy Final Appraisal. http:// www.icer-review.org/publications-and-resources/reports/.

46. Briggs A, Claxton K, Sculpher M: Decision modelling for health economic evaluation. 1st edition. Oxford: Oxford Univ. Press; 2006.

47. Andersson SO, Rashidkhani B, Karlberg L, Wolk A, Johansson JE: Prevalence of lower urinary tract symptoms in men aged 45-79 years: a populationbased study of 40000 Swedish men. BJU Int 2004, 94(3):327-331.

48. Horwitz EM, Thames HD, Kuban DA, Levy LB, Kupelian PA, Martinez AA, Michalski JM, Pisansky TM, Sandler HM, Shipley WU, Zelefsky MJ, Hanks GE, Zietman AL: Definitions of biochemical failure that best predict clinical failure in patients with prostate cancer treated with external beam radiation alone: a multi-institutional pooled analysis. The J of Urol 2005, 173(3):797-802.

49. Rogowski WH, Landauer $M$, John J: Decision-analytical modelling of costs per QALY in the context of the German Social Law. Gesundheitswesen 2009, 71(11):739-750.

50. Grosse SD: Assessing cost-effectiveness in healthcare: history of the $\$ 50,000$ per QALY threshold. Expert Rev Pharmacoecon Outcomes Res 2008, 8(2):165-178.

51. Graf von der Schulenburg JM, Greiner W, Jost F, Klusen N, Kubin M, Leidl R, Mittendorf T, Rebscher H, Schoeffski O, Vauth C, Volmer T, Wahler S, Wasem J, Weber C, Hanover Consensus Group: German recommendations on health economic evaluation: third and updated version of the Hanover consensus. Value Health 2008, 11(4):539-544.

52. Hayes JH, Ollendorf DA, Pearson SD, Barry MJ, Kantoff PW, Lee PA, McMahon PM: Observation versus initial treatment for men with localized, low-risk prostate cancer: a cost-effectiveness analysis. Ann Intern Med 2013, 158(12):853-860.

53. Keegan KA, Dall'Era MA, Durbin-Johnson B, Evans CP: Active surveillance for prostate cancer compared with immediate treatment: an economic analysis. Cancer 2012, 118(14):3512-3518.

54. Ploussard G, Epstein Jl, Montironi R, Carroll PR, Wirth M, Grimm M-O, Bjartell AS, Montorsi F, Freedland SJ, Erbersdobler A, van der Kwast TH: The contemporary concept of significant versus insignificant prostate cancer. Eur Urol 2011, 60(2):291-303.

55. Epstein Jl, Walsh PC, Brendler CB: Radical prostatectomy for impalpable prostate cancer: the Johns Hopkins experience with tumors found on 
transurethral resection (stages $\mathrm{T} 1 \mathrm{~A}$ and $\mathrm{T} 1 \mathrm{~B}$ ) and on needle biopsy (stage T1C). J Urol 1994, 152(5 Pt 2):1721-1729.

56. Oliveira IS, Pontes-Junior J, Abe DK, Crippa A, Dall'oglio MF, Nesralah AJ, Leite KR, Reis ST, Srougi M: Undergrading and understaging in patients with clinically insignificant prostate cancer who underwent radical prostatectomy. Int Braz J Urol 2010, 36(3):292-299.

57. Sutcliffe P, Hummel S, Simpson E, Young T, Rees A, Wilkinson A, Hamdy F, Clarke N, Staffurth J: Use of classical and novel biomarkers as prognostic risk factors for localised prostate cancer: a systematic review. Health Technol Assess 2009, 13(5):1-219. iii, xi-xiii.

58. Choi WW, Gu X, Lipsitz SR, D'Amico AV, Williams SB, Hu JC: The effect of minimally invasive and open radical prostatectomy surgeon volume. Urol Oncol 2012, 30(5):569-576.

59. Vickers AJ, Bianco FJ, Serio AM, Eastham JA, Schrag D, Klein EA, Reuther AM, Kattan MW, Pontes JE, Scardino PT: The surgical learning curve for prostate cancer control after radical prostatectomy. I Natl Cancer Inst 2007, 99(15):1171-1177.

60. Fryback DG, Lawrence WF Jr: Dollars may not buy as many QALYs as we think: a problem with defining quality-of-life adjustments. Med Decis Making 1997, 17(3):276-284.

61. Welte $R$, Feenstra $T$, Jager $H$, Leidl R: A decision chart for assessing and improving the transferability of economic evaluation results between countries. Pharmacoecon 2004, 22(13):857-876.

62. Wilt TJ, MacDonald R, Rutks I, Shamliyan TA, Taylor BC, Kane RL: Systematic review: comparative effectiveness and harms of treatments for clinically localized prostate cancer. Ann Intern Med 2008, 148(6):435-448.

63. Becker A, Kluth LA, Beermann S, Seiler D, Recker F, Chun FK, Weissbach L: 272 The HAROW study-an observational health service study, capturing current low-risk-prostate cancer treatment practice patterns in Germany. Eur Urol Suppl 2013, 12(1):e272.

64. Wiegel T, Albers P, Bussar-Maatz R, Gottberg A, Harter M, Kieser M, Kristiansen G, Nettekoven G, Martus P, Schmidberger H, Wellek S, Stöckle M: PREFERE-the German prostatic cancer study: questions and claims surrounding study initiation in January 2013. Urologe A 2013, 52(4):576-579.

65. Koerber F, Rolauffs B, Rogowski W: Early evaluation and value-based pricing of regenerative medicine technologies. Regen Med 2013, 8(6):747-758.

66. Feldman-Stewart D, Capirci C, Brennenstuhl S, Tong C, Abacioglu U, Gawkowska-Suwinska M, van Gils F, Heyda A, Igdem S, Macias V, Grillo IM, Moynihan C, Pijls-Johannesma M, Parker C, Pimentel N, Wördehoff H: Information for decision making by patients with early-stage prostate cancer: a comparison across 9 countries. Med Decis Making 2011, 31(5):754-766

doi:10.1186/1472-6963-14-163

Cite this article as: Koerber et al:: The cost-utility of open prostatectomy compared with active surveillance in early localised prostate cancer. BMC Health Services Research 2014 14:163.

\section{Submit your next manuscript to BioMed Central and take full advantage of:}

- Convenient online submission

- Thorough peer review

- No space constraints or color figure charges

- Immediate publication on acceptance

- Inclusion in PubMed, CAS, Scopus and Google Scholar

- Research which is freely available for redistribution 